\title{
Prenatal Diagnosis of Circular Shunt: A Rare Complication of Ebstein's Anomaly
}

\author{
Diagnóstico Pré-Natal de Shunt Circular: Rara Complicação da Anomalia de Ebstein
}

Marcia Ferreira Alves Barberato ${ }^{1}$, Silvio Henrique Barberato ${ }^{1}$

${ }^{1}$ CardioEco Cardiovascular Diagnostic Center, Curitiba, PR, Brazil.

Circular shunt is a condition in which blood from a cardiac chamber is diverted through the heart to return to the original chamber without reaching the pulmonary capillary bed. A 27-year-old pregnant woman, G1, P0, A0, 25 gestational weeks, was referred for fetal echocardiography due to an increased cardiac area on morphological obstetric ultrasound in the second trimester. She had no comorbidities, and early pregnancy ultrasound findings were normal.

A 25-week fetal echocardiogram showed cardiomegaly, attachment of the tricuspid valve septal leaflet to the interventricular septum, and significant tricuspid insufficiency compatible with Ebstein's anomaly (Figure 1). A small pericardial effusion was seen and Huhta cardiovascular score was 6. An adequate pulmonary artery diameter (Z-score 1.9) was noted (Figure 2) with no anterograde flow, only retrograde flow coming from the ductus arteriosus characteristic of a circular shunt. At 29 gestational weeks, fetal hydrops was observed, with zero umbilical artery diastolic flow and a Huhta score of 4 (Figure 3). Fetal death occurred at 30 gestational weeks.

\section{Authors' contributions}

Research conception and design: MFAB; Data collection: MFAB; Data analysis and interpretation: MFAB, SHB; Manuscript writing: MFAB, SHB; Critical review of the manuscript for important intellectual content: MFAB, SHB.

\section{Conflict of interest}

The authors have declared that they have no conflict of interest.

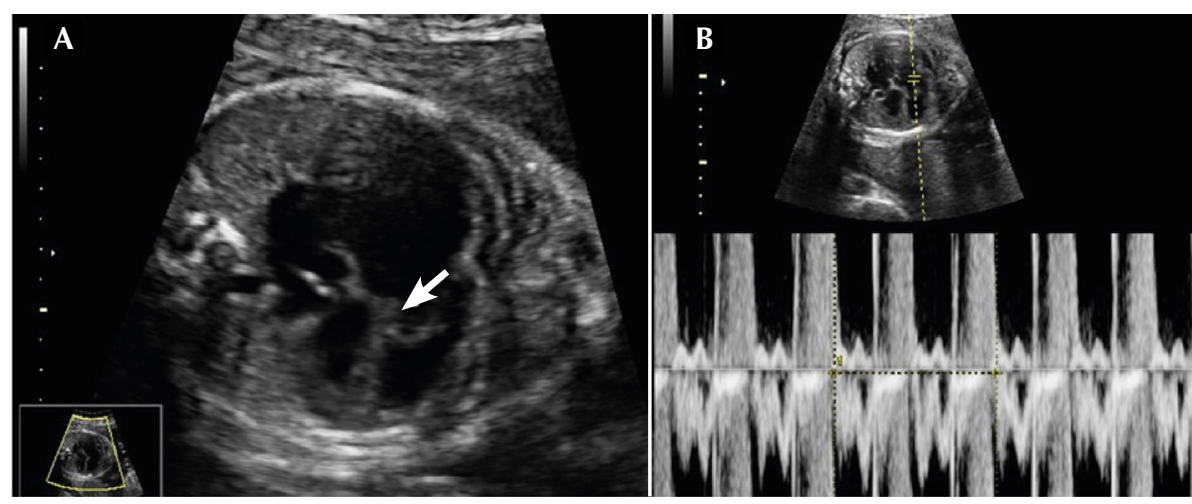

Figure 1 - Four-chamber view of a 25-week-old fetus showing $(A)$ attachment of the tricuspid valve septal leaflet (white arrow) with an enlarged right atrium and (B) tricuspid insufficiency on pulsed Doppler.

\section{Keywords}

Echocardiography, Doppler; Prenatal Diagnosis; Ebstein's Anomaly.

Mailing Address: Silvio Henrique Barberato •

Avenida República Argentina, 1.336, sala 215. CEP 80620-010 - Curitiba,

PR, Brazil.

silviohb@cardiol.br

Manuscript received 10/13/2021; revised 10/15/2021; accepted 11/3/2021. 


\section{Images}
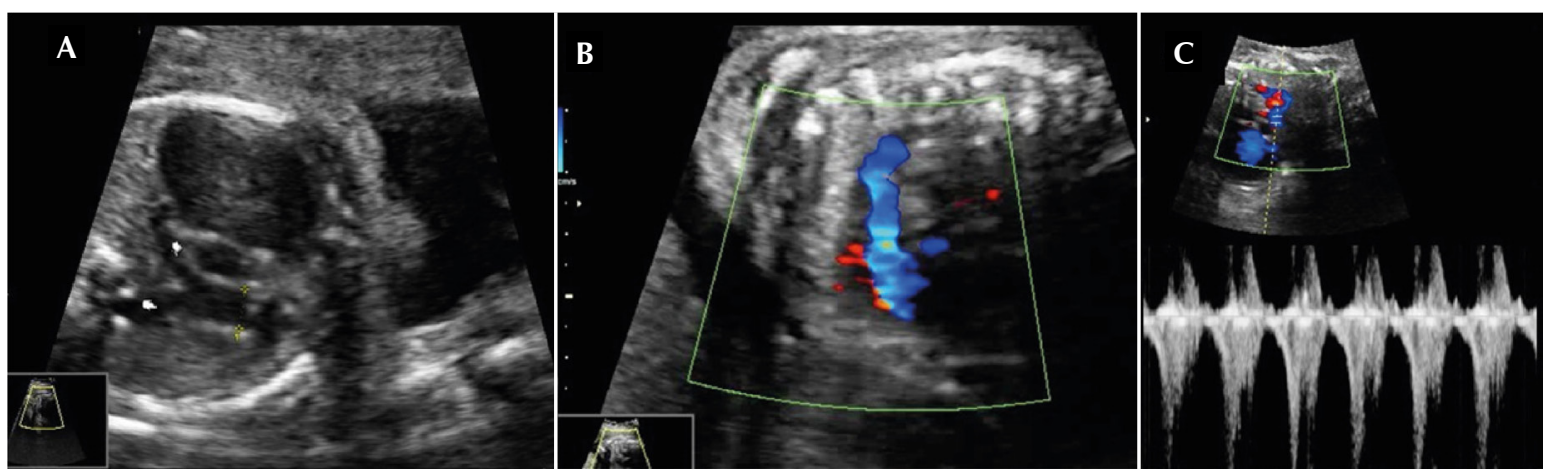

Figure 2 - Right ventricular outflow view showing (A) adequate pulmonary artery diameter and (B) reverse flow in the pulmonary artery on color Doppler and (C) pulsed Doppler.
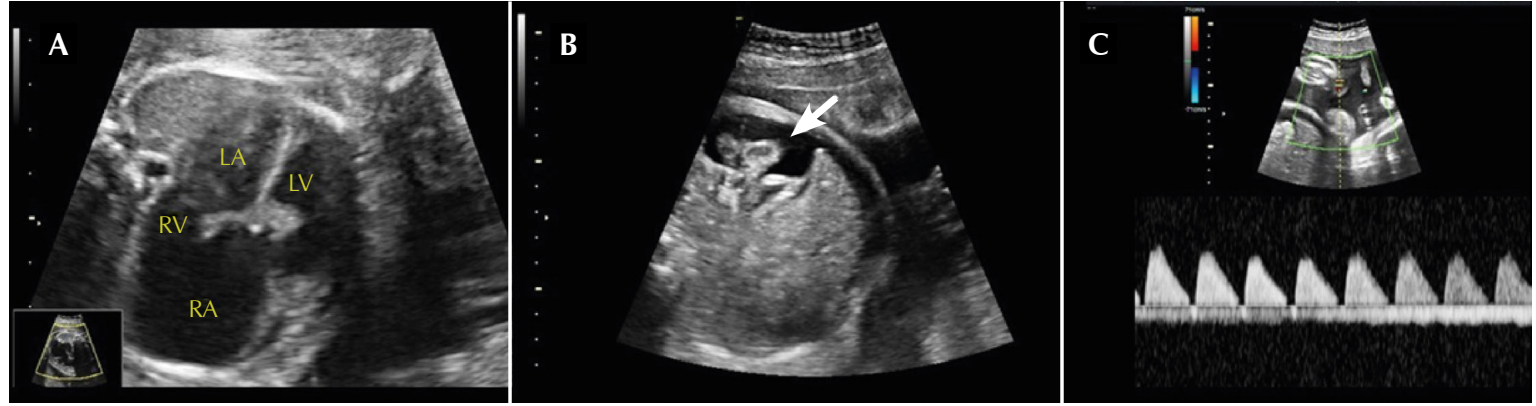

$L A$, left atrium; $L V$, left ventricle; $R A$, right atrium; $R V$, right ventricle.

Figure 3 - Two-dimensional and Doppler images of a 29-week fetus showing (A) right atrial enlargement, $(B)$ ascites (white arrow), and (C) zero umbilical diastolic flow. 